\title{
Dynamic Management and Schedule Risk in Rail Transit Projects based on 4D-BIM
}

\author{
Lina LIU, Hua ZHENG \& Yi ZHANG \\ Shijiazhuang Institute of Railway Technology, Shijiazhuang Hebei 050061, China
}

\begin{abstract}
Rail transit project is system engineering with long construction period which involves different specialties and numerous departments. Project management and schedule control have a great impact on economic interests and social benefits. In this paper, project management model with comprehensive application of $4 \mathrm{D}-\mathrm{CAD}$ and BIM technology is set for $4 \mathrm{D}-\mathrm{BIM}$ rail transit project. Then, the risk earlywarning model is proposed which is built on visual dynamic and integrating project management model. These provide a new method to improve management level and progress controlling ability of rail transit project.
\end{abstract}

KEYWORD: BIM; 4D-CAD; Rail Transit; schedule risk early warning

\section{INTRODUCTION}

Rail transit project is complicated system engineering. It needs to consume a large amount of manpower, material and shift of machinery in due date constraint. In order to complete the project with high standard in the employer's requirements time, the construction side needs to manage the project scientifically and control the schedule effectively. Rail transit project not only is large in scale but also is long in lifecycle. It also involves many professional including architecture, structure, irrigation, electricity, rail, communication, integrated supervisory etc. In the long construction process, due to changes in external conditions, there will be a lot of changes of engineering. Although most of the changes are relatively simple, but they still involve multiple specialty and department.

At present, rail transit project uses mainly the two-dimensional drawings and paper documents for construction management of engineering project in our country. This has hindered seriously the effective communication between stakeholders. Once the preliminary design error has been found, the poor communication between all participants will lead to redundant construction, waste of resources, rework and other issues. In order to solve the above problems, it is necessary to develop a new platform to help enterprises to control costs effectively, analysis risk, assure the quality and completion time of projects, and to promote the rapid development of fine construction and management in construction industry.

In this paper, the technology of 4D-CAD and BIM is introduced into the field of construction schedule risk early warning. Through building the 4D information model of construction, the construction information is linked dynamically. And by applying the reasonable risk analysis methods, we can get risk prediction of the project schedule which is dynamic and visual. It can not only optimize the project risk management methods but also guide the construction management for effective allocation of resources.

\section{THE CONCEPT AND THEORIES OF 4D-BIM}

4D-BIM refers to 4D-CAD technology and BIM technology [1]. 4D-CAD technology which introduces time information into three-dimensional model can simulate intuitively the whole process of the construction in the dynamic change form of three-dimensional model, to facilitate the schedule management and optimize process control [2].

BIM is building information modeling. It is based on the 3D digital technology [3] and integrated all kind of information of each profession, each participant and different stages of the project in lifecycle [4]. It can realize relevance and sharing information. It is a kind of method innovation on building design, construction and management. BIM is not just a 3D model, but also include much 
property information of component material, mechanics performance, construction resources and so on. Using BIM as a platform of communication, the participants of the project can share data on the same platform. Thus it can decrease the number of requests for information between the more professions and shorten the response time for information. Especially for rail transit project which is huge, complex and has many functions, it is particularly important that applying BIM to implement coordination management between all professions [5-6].

The integrated use of 4D- BIM technology has more advantages than previous management methods which are based on 2D drawing and paper documents [7]. First of all, it solves the problem of information communication. Because of using a single engineering data source, BIM ensure that the engineering data is accuracy and consistency. It also can coordinate the design problem about architecture, structure, equipment and so on which is often appeared in the process of the construction. Second, it can simulate the actual construction. [8] The 4D simulation according to the schedule can guide the construction to determine the reasonable construction scheme. [9]

\section{THE RESEARCH OF INFORMATION MODEL OF RAIL TRANSIT PROJECTS BASED ON 4D-BIM}

According to the application requirement of rail transit project, comprehensive model must meet the following three characteristics:

(1) The integrity of the model information. According to the application purpose, the scope and the detail of the expression of information should be determined so that to avoid redundant or missing of information. In general component should contain 3D geometry information, such as location, shape, etc. It also should include the engineering attribute information, such as type of component, component of material, type of structure, performance of project, etc. And schedule, technique, quality, labor, cost, materials, resources and so on should be included.

(2) The correlation of model information. The participants of the project share information each other. Document's submitting, reviewing, approving and using can be completed through network. Due to the parametric design, BIM make the design changes between different units to get fast delivery. If an object of the model has been changed or an engineering program has been modified, it can update automatically all object associated with it.

(3) The unity of model information. Because the application of BIM requires a series of software, the unified modeling tools and the same information interoperability standards are needed. Such model's information is unity. And the same information don't need input repeatedly.

\subsection{BIM Modeling Technology}

BIM model is different from the CAD drawings of 2D representation. It is also different from general 3D renderings. It's 3D drawing with lots of engineering properties. The main integrated model (As shown in Figure 1) should be set up according drawing first. And then the construction model should be established according to BIM application goal and needs.

(1) The main integrated model. The BIM model consists of building model, structure model, pipeline model and mechanical model. Different models which are established according to BIM application goal can express model's components and their properties. The 3D building model which integrated the design, construction and management information realize the parametric create and display of 3D model, correlation, view, edit, and extension of building components and information of material, schedule, cost, quality, safety and so on.

(2) The construction model.

The construction model is needed after the main integrated model was established, so that for followup collision detection. Horizontal transportation tools such as excavator, payload, for example, the mechanical arm can rotation within a certain radius. So the entity of the three-dimensional shape description at a certain moment does not reflect the space requirements of the work. So we should ascertain its space requirements according to its movement characteristics and the whole model with its rotating parts.

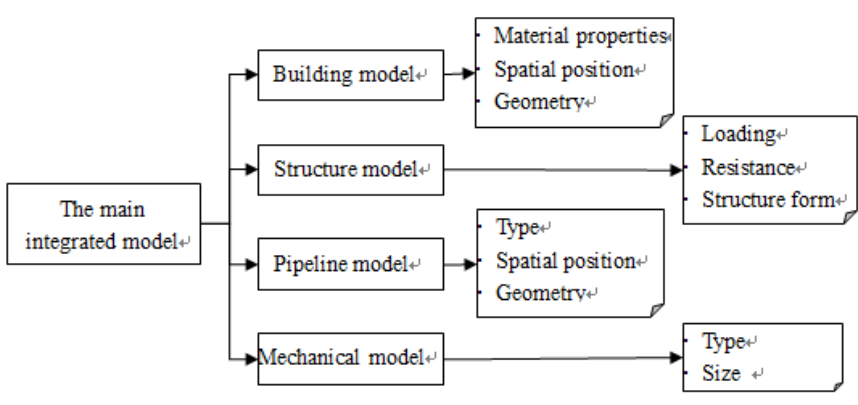

Figure 1. The composition of the 3D integrated model

\subsection{D Virtual Construction Technology}

Combined BIM model and schedule, the progress of the model can be displayed dynamically according the schedule.

We can fix up the construction site, stack materials and preview the machinery route in advance. Simulation the whole construction progress makes all parties involved in the project to have a more intuitive understanding of the schedule. So the 
dynamical integration and visualization construction management can be achieved (As shown in Figure2).

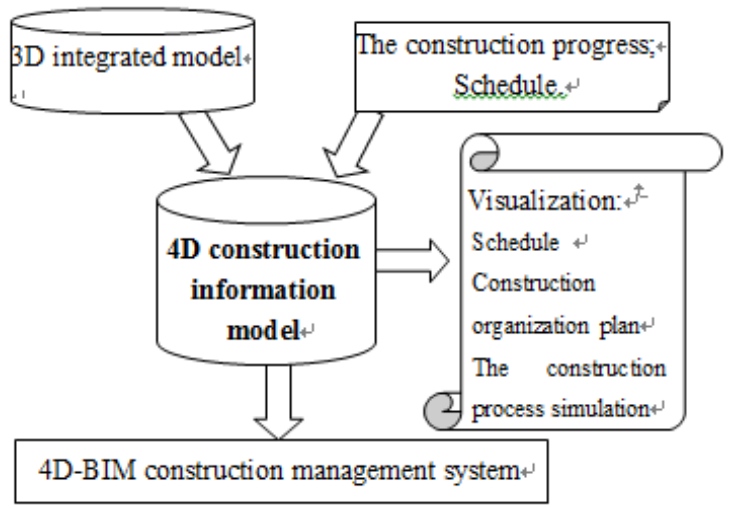

Figure 2. The diagram of the 4D-BIM dynamic management

The geometric component and schedule parameters were linked to display the construction process vividly. The dynamic management of the schedule, artificial, equipment and space layout of the project can be achieved. What the participants of the project collaborative work is also achieved. The participants of project can share information. Submission, review, approval and use of the documents, drawings and visual files can implement based on network. The participants of project can work together based network.

Implementation of the construction process on the computer can predict the potential problems of the project before constructing. It includes the experiment of construction method, simulation of construction process and optimization of construction scheme, and so on.

\section{SCHEDULE RISK MODEL IN RAIL TRANSIT PROJECTS BASED ON 4D-BIM}

4D-BIM model contains all kinds of information of construction project in whole life cycle such as architecture, structure, economy, management, and so on. It can provide comprehensive and accurate data for the risk evaluation of construction schedule. Contractor can make a more accurate risk assessment for rail transit project based on 4D-BIM model, so that they can make the corresponding risk countermeasure.

The early warning model of construction project schedule risk based on 4D-BIM (As shown in Figure 3)take building BIM model as information foundation and take BIM case base as data source. Applying reasonable risk analysis method makes the dynamic and visible risk prediction to the project schedule. So it can optimize the risk management method and guide the construction manager to deploy resources effectively.

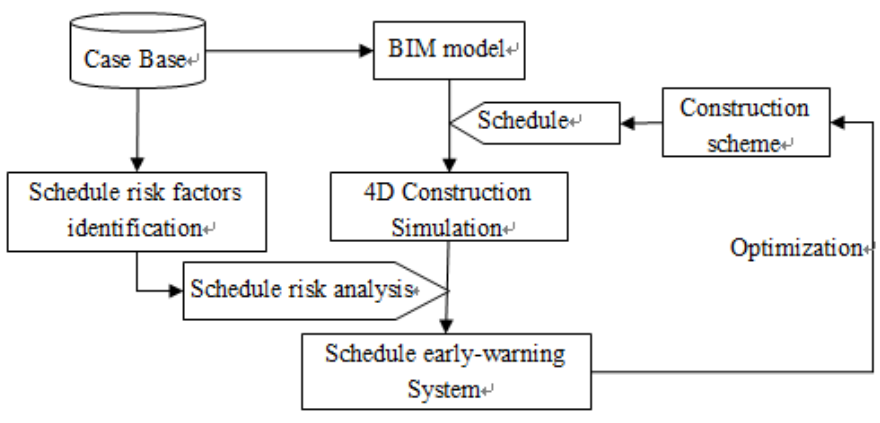

Figure 3. The early warning model of construction project schedule risk based on 4D-BIM

The early warning model of schedule risk is actually a process of identifying risk gradually. Then the risk results that be analyzed will be used to reckon risk reason. And then the early warning of construction schedule risk can be completed. The construction of the model consists of four parts: the construction of case base, the identification of schedule risk factors, the analysis and evaluation of schedule risk factors and the early warning of schedule risk.

(1) The management of case base. All kinds of rail transit projects should be stored in BIM case base according to IFC data standard. ${ }^{[10]}$ The case base should also be daily operated and maintained, such as recording construction project information, updating project data, inserting new project cases, searching cases, deleting project information and so on. Because all projects had been completed, the risk factors which impacted construction schedule were data that had been recorded and could be searched.

(2) The identification of schedule risk factors. We can identify the schedule risk factors using the method of case-based reasoning, and find the most similar cases in the BIM case base. ${ }^{[11-12]}$ We can get new risk factors of case schedule and classify them by comparing with the factors which impacted the completed cases.

(3) The analysis and evaluation of schedule risk factors. By using the powerful schedule management software (such as P3, MS Project) to design construction process, we can evaluate the risk of construction schedule. The distribution of schedule probability and time of each working procedure can be determined according to the schedule risk factors. After simulating for some times, all procedures were superposed. Then we can get the distribution curve of schedule probability and time of total duration for the early warning of schedule risk.

(4) The early warning of schedule risk. According to the results from analysis of schedule risk, we can build an early warning system of construction schedule risk. We also can realize the 4D visualization of the schedule early-warning by means of 4D-BIM model. Take appropriate response measures according to the results of risk early warning. Work out the different countermeasures to 
different levels of risk. Adding the risk information in the case base of risk early warning is easy to guide future risk management.

\section{SUMMARY}

By introducing 4D-BIM into the rail transit projects, we build a 4D construction information model to realize the visual dynamic management of construction process. The early warning model of construction project schedule risk based on 4D-BIM is put forward by use of the parametric design and powerful data support of BIM. It also helps the contractor to find out the possible problems in the construction timely, so that as soon as possible to develop preventive measures, and optimize the construction scheme, so as to improve the management level and the ability to schedule control of rail transit project.

\section{REFERENCES}

[1] C.Kam, M,Fischer, R.Hanninen, A.Karjalainen \& J.Laitinen. The product model and Forth Dimesion project. Itcon-Special Issue IFC-product models for the AEC arena, 2003(8): 137-166.

[2] Kathleen McKinney, Jennifer Kim', Martin Fischer, Craig Howard. Interactive 4D-CAD. New York; Computing in Civil Engineering, 1996.

[3] WangG.B., ZhangY, JiangZ.J. Benefits situation to stakeholders using BIM in preconstruction stage of projects. Journal of Shandong Jianzhu University. 2009, 24(5):438-459.

[4] ZhangJ.P., CaoM., ZhangY. A 4D Construction Management System based on IFC standard and Engineering Information Model. Engineering Mechanics, 2005, 22:220-227

[5] McGran-Hill Construction. BIM Market Review. BIMTransforming Design and Construction. 2008: 14-17.

[6] ZhangY, ZhouX.N, Analysis of present situation and Prospect of subway and underground engineering risk management. Construction and Architecture, 2010, 2:2731.

[7] ShiL.N, HuX. W, Design and application of construction organization and management of teaching building project of 4D- based on BIM, View of science and technology, 2012,23.

[8] HeG. P, BIM general. BeiJing: China Architecture \& Building Press, 2011.

[9] Becerik, G. et al. BIM-Enabled Virtual and Collaborative Construction Engineering and Management. Journal of Professional Issues in Engineering Education and Practice. 2012, 138(3): 234-245.

[10] Zhang J. P, Study on BIM and the data integrated platform based on IFC, The Fourteenth National Conference on engineering design of computer application set, HangZhou, 2008.

[11] Nasir et al. Evaluating risk in construction-schedule model (ERIC-S): Construction schedule risk model. Journal of Construction Engineering and Management-ASCE, 2003, 129(5): 518-527.

[12] Francis K. Adams. Risk perception and Bayesian analysis of international construction contract risks: The case of payment delays in a developing economy. International Journal of Project Management, 2008, 26(2):138-148. 